\title{
Avaliação dos efeitos de fontes de fósforo na dieta sobre parâmetros do meio ruminal e eficiência de síntese microbiana, digestibilidade dos nutrientes e fósforo plasmático em bovinos ${ }^{1}$
}

\author{
Julio Cezar Barreto2 , Antonio Ferriani Branco ${ }^{3}$, Geraldo Tadeu dos Santos ${ }^{3}$, Vanessa Jaime \\ de Almeida Magalhães ${ }^{2}$, Sabrina Marcantonio Coneglian ${ }^{2}$, Silvana Teixeira ${ }^{2}$ \\ 1 Trabalho financiado pelo CNPq. \\ 2 Pós-Graduação em Zootecnia - UEM - Av. Colombo, 5790 - CEP: 87020-900. \\ ${ }^{3}$ Departamento de Zootecnia - UEM - Av. Colombo, 5790 - CEP: 87020-900. Pesquisador CNPq.
}

RESUMO - Este trabalho foi conduzido com os objetivos de avaliar o efeito de fontes de fósforo em dietas para bovinos em crescimento sobre o coeficiente de digestibilidade parcial e total dos nutrientes, os parâmetros ruminais, a eficiência de síntese microbiana e os níveis plasmáticos de fósforo. Foram utilizados quatro bovinos castrados, raça Holandesa Preto e Branco (280 kg de peso vivo), com cânula ruminal e duodenal, em delineamento quadrado latino $4 \times 4$, com quatro fontes de fósforo (fosfato bicálcico - BIC; superfosfato triplo - SPT; fosfato monoamônio - MAP; e fosfato de rocha Araxá FRA). As fontes de fósforo não afetaram a ingestão, o fluxo fecal, as digestibilidades ruminal, duodenal e total de matéria seca, matéria orgânica, proteína bruta, fibra em detergente neutro e carboidratos não-fibrosos. A absorção de fósforo do fosfato de rocha Araxá foi menor e diferiu da absorção do fosfato bicálcico e do fosfato monoamônio. Os animais que receberam fosfato de rocha Araxá apresentaram maiores ingestão, fluxo fecal, fluxo duodenal, desaparecimento ruminal e desaparecimento fecal de flúor (F). A utilização de fosfato de rocha Araxá resultou em níveis de flúor na dieta superiores aos recomendados para evitar sua toxidez. As fontes de fósforo não alteraram os níveis plasmáticos de fósforo nem a ingestão de nitrogênio, a eficiência de síntese microbiana e a composição das bactérias ruminais. Também não influenciaram o pH ruminal e as concentrações de $\mathrm{NH}_{3}$-ruminal. Estes resultados indicam que é possível o uso do superfosfato triplo e do fosfato monoamônio em substituição ao fosfato bicálcico.

Palavras chave: fosfato bicálcico, fosfato de rocha, fosfato monoamônio, síntese microbiana, superfosfato triplo

\section{Evaluation of different phosphorus sources in the diet on ruminal parameters, microbial synthesis, nutrient apparent digestibility and plasma phosphorus in cattle}

ABSTRACT - This study was carried out to evaluate the effects of different phosphorus sources, in diets of growing cattle, on apparent partial and total nutrient digestibility; ruminal parameters; microbial efficiency synthesis and plasma phosphorus. Four Holstein steers weighting $280 \mathrm{~kg}$ and implanted with ruminal and duodenal cannulas were used. The experimental design was a $4 \times 4$ Latin Square and treatments were four supplemental phosphorus sources in the diet as follows: dicalcium phosphate (DP), supertriple phosphate (SP), monoammonium phosphate (MP) and Araxa rock phosphate (ARP). Phosphorus sources did not affect intake, fecal flow, apparent ruminal and intestinal digestibility of dry matter (DM), organic matter (OM), crude protein (CP), neutral detergent fiber (NDF) and non fiber carbohydrates (NFC). There was a lower phosphorus apparent absorption for ARP, differing of DP and MP. Animals receiving ARP showed higher intake, fecal flow, duodenal flow, ruminal disappearance and total disappearance for fluoride. Animals receiving ARP presented fluoride levels higher than those acceptable to avoid toxicity. Phosphorus sources did not affect plasma phosphorus, nitrogen intake, microbial efficiency synthesis and ruminal bacteria composition. Treatments did not affect ruminal $\mathrm{pH}$ and ruminal ammonia concentration. These results show a possible use for supertriple phosphate and monoammonium phosphate to replace dicalcium phosphate.

Key Words: dicalcium phosphate, monoammonium phosphate, microbial synthesis, rock phosphate, supertriple phosphate 


\section{Introdução}

Entre os minerais essenciais aos animais domésticos, o fósforo se destaca, tanto por suas funções no organismo animal quanto pelo seu custo, que onera as rações e misturas minerais.

O fósforo é amplamente estudado e participa de muitas funções vitais ao organismo (Karn, 2001). É o segundo mineral mais encontrado na composição dos tecidos animais: aproximadamente $1 \%$ do peso corporal dos animais é constituído de fósforo, dos quais $80 \%$ estão nos ossos e nos dentes. Os $20 \%$ restantes estão distribuídos nos tecidos moles e envolvidos no metabolismo, principalmente nas células vermelhas do sangue, músculos e sistema nervoso (Underwood \& Suttle, 1999).

Segundo Barcellos (1998), a absorção de fósforo nos pré-estômagos de ruminantes ocorre por transferência passiva através do epitélio ruminal. A maior parte da absorção ocorre na porção cranial do duodeno, tanto em ruminantes como em não-ruminantes (Rosol \& Capen, 1997), onde o pH é suficientemente baixo para permitir a formação de fosfato solúvel (Ben-Ghedalia et al., 1975).

No rúmen ocorrem altas concentrações de fósforo, que variam de 200 a $600 \mathrm{mg} / \mathrm{L}$ (Witt \& Owens, 1983), e 50 a $70 \%$ deste fósforo tem origem endógena, ou seja, foi secretado pela saliva.

O fósforo é um mineral essencial ao crescimento microbiano e importante constituinte das paredes das células microbianas. Segundo Chicco et al. (1965) as taxas máximas de crescimento microbiano são obtidas quando a concentração no meio de incubação é de 40 a $80 \mathrm{mg}$ P/L.

Os ruminantes possuem a habilidade de sobreviver e muitas vezes produzir carne e leite sem uma fonte extra de proteína verdadeira na ração, por terem capacidade de síntese protéica microbiana no rúmen. A célula microbiana que passa do rúmen e é digerida no abomaso e intestino dos ruminantes constitui a principal fonte de proteína para estes animais, pois contém perfil bem balanceado de aminoácidos essenciais (Forbes \& France, 1993).

Este trabalho foi conduzido para avaliar o fosfato bicálcico, o superfosfato triplo (fosfato monocálcico), o fosfato monoamônio e o fosfato de rocha de Araxá como fontes de fósforo e seus efeitos sobre a digestibilidade aparente dos nutrientes, a absorção parcial e total do fósforo, a concentração plasmática de fósforo, a eficiência de síntese microbiana, o pH e a amônia ruminal em bovinos.

\section{Material e Métodos}

O experimento foi realizado no setor de Avaliação de Alimentos para Animais Ruminantes da Fazenda Experimental de Iguatemi (FEI) e as análises químicas, no Laboratório de Análise de Alimentos e Nutrição Animal (LANA), pertencentes à Universidade Estadual de Maringá.

Foram utilizados quatro bovinos, machos castrados, da raça Holandesa Preto e Branca, com $280 \mathrm{~kg}$ de peso vivo médio, com cânulas ruminal e duodenal (tipo T-simples).

Os animais foram mantidos em barracão de alvenaria totalmente coberto, em baias individuais com $8,75 \mathrm{~m}^{2} \mathrm{de}$ área útil e piso concretado. As baias eram providas de comedouro de polietileno individuais e bebedouros automáticos, um para cada duas baias. Foram alimentados duas vezes ao dia e pesados no início de cada período experimental, com o objetivo de ajustar o consumo de matéria seca.

A dieta experimental (Tabelas 1 e 2 ) foi a mesma para todas as fontes de fósforo e fornecida para atender $1,5 \mathrm{vez}$ a exigência de energia líquida de mantença (NRC, 1996) e permitir ganho de peso vivo próximo de $0,5 \mathrm{~kg} / \mathrm{dia}$. As fontes de fósforo avaliadas - fosfato bicálcico (BIC); superfosfato triplo (SPT); fosfato monoamônio (MAP) e fosfato de rocha de Araxá (FRA) - foram colocadas diretamente no rúmen durante a alimentação da manhã e forneciam $8 \mathrm{~g}$ de fósforo $(0,12 \%$ na MS da dieta total), representando $60 \%$ do fósforo total.

Os períodos experimentais tiveram duração de 21 dias, com cinco dias de coleta de amostras (alimentos, sobras, digesta duodenal, fezes, sangue, líquido ruminal e conteúdo ruminal), realizadas no período entre o $17^{\circ}$ e o $21^{\circ}$ dia.

O óxido de cromo foi utilizado como indicador externo para determinar o fluxo da digesta duodenal e a produção fecal, ministrado via intra-ruminal durante a alimentação da manhã, em dose diária de $10 \mathrm{~g}$, a partir do sétimo dia de cada período.

Com o objetivo de determinar a digestibilidade parcial e total de matéria seca, matéria orgânica, proteína bruta, fibra em detergente neutro e a absorção aparente de fósforo, foram coletadas amostras do volumoso, do concentrado, das sobras, da digesta duodenal (300 mL) e das fezes (50 g).

As amostras foram conservadas a $-20^{\circ} \mathrm{C}$ para posterior processamento e análises. As amostras da digesta duodenal e das fezes foram coletadas por um período total de quatro dias, em intervalos de 6 horas, com aumento de 1 hora a cada dia, totalizando 12 amostras de digesta duodenal e 12 de fezes por animal e período. 
Tabela 1 - Composição dos alimentos das dietas

\begin{tabular}{|c|c|c|c|c|c|c|c|c|}
\hline Alimento & $\begin{array}{l}\text { Proteína } \\
\text { bruta }\end{array}$ & $\begin{array}{c}\text { Nutrientes digestíveis } \\
\text { totais }\end{array}$ & $\begin{array}{l}\text { Carboidratos } \\
\text { não-fibrosos }\end{array}$ & $\begin{array}{l}\text { Extrato } \\
\text { etéreo }\end{array}$ & $\begin{array}{c}\text { Fibra em detergente } \\
\text { neutro }\end{array}$ & Cálcio & Fósforo & Flúor \\
\hline Silagem de milho & 10,42 & 65,00 & 19,60 & 2,36 & 61,30 & 0,17 & 0,16 & \\
\hline Casca de soja & 13,87 & 80,00 & 5,38 & 1,50 & 72,54 & 0,47 & 0,10 & \\
\hline Casca de algodão & 5,23 & 45,00 & 1,62 & 1,54 & 89,05 & 0,08 & 0,05 & \\
\hline Uréia & 280,00 & 0,00 & 0,00 & 0,00 & 0,00 & 0,00 & 0,00 & \\
\hline \multicolumn{6}{|l|}{ Fosfato bicálcico } & 23,98 & 18,00 & 0,14 \\
\hline \multicolumn{6}{|l|}{ Superfosfato triplo } & 14,00 & 21,90 & 0,50 \\
\hline \multicolumn{6}{|c|}{ Fosfato monoamônio } & 1,73 & 24,00 & 0,68 \\
\hline \multicolumn{6}{|c|}{ Fosfato de rocha de Araxá } & 24,61 & 10,60 & 1,02 \\
\hline \multicolumn{6}{|c|}{ Suplemento mineral ${ }^{1}$} & 10,00 & 0,00 & 0,00 \\
\hline
\end{tabular}

${ }^{1}$ Composição do suplemento mineral: $1,2 \%$ de S; $1,2 \%$ de $\mathrm{Mg} ; 10 \%$ de Na; $10 \%$ de Ca; 30 ppm de Co; 800 ppm de Cu; 50 ppm de I; 1.200 ppm de Mn; 12 ppm de Se; 3.200 ppm de Zn.

Tabela 2 - Composição da dieta experimental (\% MS)

\begin{tabular}{|c|c|c|c|c|c|c|}
\hline \multicolumn{3}{|l|}{ Alimento } & \multicolumn{4}{|c|}{$\%$ na MS } \\
\hline \multicolumn{3}{|c|}{ Silagem de milho } & \multicolumn{3}{|c|}{16,38} & \\
\hline \multicolumn{3}{|c|}{ Casca de soja } & \multicolumn{3}{|c|}{34,45} & \\
\hline \multicolumn{3}{|c|}{ Casca de algodão } & \multicolumn{3}{|c|}{47,40} & \\
\hline \multicolumn{3}{|c|}{ Uréia } & \multicolumn{3}{|c|}{1,17} & \\
\hline \multicolumn{3}{|c|}{ Suplemento mineral } & \multicolumn{3}{|c|}{0,60} & \\
\hline & PB & NDT & $\mathrm{CNF}$ & EE & FDN & $\mathrm{P}$ \\
\hline $\begin{array}{l}\text { Dieta } \\
\text { experimental }\end{array}$ & 12,24 & 59,54 & 5,83 & 1,63 & 77,24 & $0,20^{1}$ \\
\hline
\end{tabular}

${ }^{1}$ Fósforo contido nos alimentos mais o fósforo das fontes suplementares

Para determinar o pH e a concentração de amônia no líquido ruminal, foram coletadas amostras do fluido ruminal (aproximadamente $100 \mathrm{~mL}$ ) no $21^{\circ}$ dia, via cânula ruminal, nos tempos $0,2,4,6$ e 8 horas após o fornecimento da primeira alimentação do dia. O tempo zero correspondeu à amostra coletada imediatamente antes da primeira refeição, e o tempo 8, imediatamente antes do fornecimento da segunda refeição.

$\mathrm{O}$ pH foi medido imediatamente após a coleta com auxílio de peagâmetro digital e, posteriormente, $50 \mathrm{~mL}$ de líquido ruminal foram acidificados com $1 \mathrm{~mL}$ de ácido sulfúrico (1:1) e armazenado a $-20^{\circ} \mathrm{C}$, para posterior análise de amônia. A concentração de amônia das amostras do líquido ruminal foi determinada pela técnica de Fenner (1965) modificada por Vieira (1980).

Para determinação da eficiência de síntese microbiana, $1,5 \mathrm{~kg}$ de conteúdo ruminal foi coletado no último dia de cada período e misturado a $500 \mathrm{~mL}$ de solução salina a $0,9 \%$ $(\mathrm{NaCl})$. A mistura foi homogeneizada em liqüidificador, coada em fralda de algodão dobrada quatro vezes e o filtrado foi armazenado a $-20^{\circ} \mathrm{C}$ para ser processado de acordo com descrições de Cecava et al. (1990).

As amostras de silagem de milho, de sobras, de digesta duodenal e de fezes foram secas em estufa com circulação forçada de ar a $55^{\circ} \mathrm{C}$ por 96 horas, processadas individual- mente em moinhos de faca com peneira com crivos de $1 \mathrm{~mm}$, e misturadas em quantidades iguais, com base no peso seco, para formar amostras compostas de digesta e fezes por animal e período.

As amostras dos alimentos utilizados nas dietas experimentais, das sobras no cocho, da digesta duodenal e das fezes foram analisadas quanto aos teores de MS, MO, PB, EE, Ca (AOAC, 1990), FDN (Van Soest et al., 1991), fósforo (Fiske \& Subbarow, 1925) e flúor por potenciometria direta com eletrodo seletivo, segundo Singer \& Armstrong (1968). O teor de cromo nas amostras da digesta duodenal e das fezes foi determinado por espectrofotometria de absorção atômica, conforme técnica descrita por Williams et al. (1962), e usado juntamente com a concentração de nutrientes para determinar o fluxo de nutrientes para o duodeno e as fezes. A partir das concentrações de cromo encontradas nas fezes e na digesta duodenal, foram calculados a produção fecal e o fluxo duodenal.

A concentração de purinas nas bactérias do rúmen e na digesta duodenal foi determinada pelo procedimento descrito por Ushida et al. (1985), com algumas modificações propostas por Bohnert et al. (1998).

O fluxo total de $\mathrm{N}$ microbiano para o duodeno (g/dia) foi estimado pela divisão da razão $\mathrm{N}$ bacteriano no rúmen:purinas no rúmen pela razão $\mathrm{N}$ na digesta duodenal: purinas na digesta duodenal e multiplicando-se este quociente pelo fluxo total individual de N. A eficiência da síntese microbiana aparente foi expressa em g de $\mathrm{N}$ microbiano/kg de matéria orgânica degradada no rúmen (MODR) e calculada pela fórmula: Efic. Sint. Mic. $(\mathrm{g} \mathrm{N} / \mathrm{kg}$ de MO) = N Mic (g/dia)/MODR (kg/dia). A eficiência da síntese microbiana verdadeira foi calculada após correção da MODR considerando o fluxo duodenal da matéria orgânica de origem microbiana.

Os carboidratos não-fibrosos (CNF) e os nutrientes digestíveis totais (NDT) foram calculados segundo equações 
propostas por Sniffen et al. (1992): $\mathrm{CNF}=100-(\% \mathrm{FDN}+$ $\% \mathrm{~PB}+\% \mathrm{EE}+\%$ cinzas); em que: $\mathrm{FDN}=$ fibra em detergente neutro; $\mathrm{PB}=$ proteína bruta $; \mathrm{EE}=$ extrato etéreo. $\mathrm{NDT}=\mathrm{PD}$ + FDND $_{\mathrm{N}}+($ EED x 2,25) $+\mathrm{CNFD}$, em que: $\mathrm{PD}=$ proteína digestível; $\mathrm{FDND}_{\mathrm{N}}=$ fibra em detergente neutro digestível corrigida para nitrogênio; $\mathrm{EED}$ = extrato etéreo digestível; $\mathrm{CNFD}=$ carboidratos não-fibrosos digestíveis. Os nutrientes digestíveis totais foram estimados pela equação de predição proposta por Weiss (1999).

No $20^{\circ}$ dia de cada período experimental, foram realizadas coletas de sangue em tubos heparinizados e, posterior obtenção do plasma, em centrífuga refrigerada a $2.500 \mathrm{x} g$, por 15 minutos. O plasma foi analisado quanto ao teor de fósforo inorgânico (Little et al., 1971).

O experimento foi conduzido em delineamento experimental quadrado latino $4 \times 4$, utilizando-se o modelo matemático:

$$
Y_{i j k}=\mu+A_{i}+P_{j}+T_{k}+e_{i j k}
$$

em que $\mu=$ média dos tratamentos; $A_{i}=$ efeito do animal $\mathrm{i}$, variando de 1 a $4 ; \mathrm{P}_{\mathrm{j}}=$ efeito do período $\mathrm{j}$, variando de $1 \mathrm{a} 4 ; \mathrm{T}_{\mathrm{k}}=$ efeito do tratamento $\mathrm{k}$, variando de $1 \mathrm{a} 4 ; \mathrm{e}_{\mathrm{ijk}}=$ erro aleatório.

Os dados foram interpretados por análise de variância, e as médias comparadas pelo teste Tukey, adotando-se 5\% de probabilidade, pelo programa SAEG (UFV, 1997).

\section{Resultados e Discussão}

O total de fósforo excretado nas fezes foi $23 \%$ maior $(\mathrm{P}<0,05)$ nos animais que consumiram as rações contendo fosfato de rocha Araxá (6,92 g/dia) em relação à média das outras três fontes, enquanto entre os fosfatos bicálcico, superfosfato triplo e fosfato monoamônio $(5,42 ; 5,78 \mathrm{e}$ $5,62 \mathrm{~g} /$ dia, respectivamente) não houve diferença $(\mathrm{P}>0,05)$.

A maior excreção fecal de fósforo (Tabela 3) pelos animais que receberam suplementação com fosfato de rocha Araxá em relação ao fosfato bicálcico foi confirmada também por Vitti et al. (2001), em novilhos mestiços recebendo fosfato bicálcico, fosfato de rocha de Patos de Minas e de Tapira como fonte suplementar de fósforo. Esses autores relataram que os animais apresentaram ingestão de 10,90; 10,54 e 10,63 g P/dia e excreção de 6,52; 8,28 e 8,16 g P/dia para bicálcico, Patos de Minas e Tapira, respectivamente, o que resulta em excreção 27 e $25 \%$ maior para as fontes de rocha, respectivamente. Ressalta-se que o fósforo excretado é constituído não somente pelo fósforo não absorvido da dieta mas também pela fração endógena (Georgievskii et al., 1982).

A absorção aparente total do fósforo foi semelhante entre os animais que receberam suplementação com fosfatos bicálcico, monoamônio e superfosfato triplo, que apresen-

Tabela 3 - Ingestão, fluxos ruminal, intestinal e fecal, desaparecimento ruminal, intestinal e total, absorção aparente ruminal, absorção aparente intestinal e absorção aparente total do fósforo e flúor

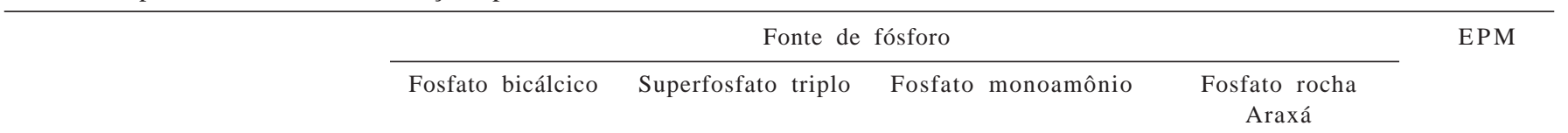

Fósforo

Ingestão (g/dia)

Fluxo duodenal (g/dia)

Fluxo fecal (g/dia)

Desaparecimento ruminal (g/dia)

Desaparecimento intestinal $(\mathrm{g} / \mathrm{dia})$

Desaparecimento total ( $\mathrm{g} / \mathrm{dia})$

Absorção aparente ruminal (\%)

Absorção aparente intestinal (\%)

Absorção aparente total (\%)
14,15
19,21
$5,42 b$
$-5,06$
13,79
$8,73 \mathrm{a}$
$-35,76$
71,79
$61,70 \mathrm{a}$

14,06
25,10
$5,78 \mathrm{~b}$
$-11,04$
19,32
$8,28 \mathrm{ab}$
$-78,52$
76,97
$58,89 \mathrm{ab}$

Ingestão $(\mathrm{g} / \mathrm{dia})$

Fluxo duodenal (g/dia)

Fluxo fecal (g/dia)

Desaparecimento ruminal (g/dia)

Desaparecimento intestinal $(\mathrm{g} / \mathrm{dia})$

Desaparecimento total (g/dia)

Absorção aparente ruminal (\%)

Absorção aparente intestinal (\%)

Absorção aparente total (\%)
$64 \mathrm{c}$

$\begin{array}{lc}64 \mathrm{c} & 182 \mathrm{bc} \\ 50,5 \mathrm{~b} & 117,5 \mathrm{~b} \\ 21,5 \mathrm{~b} & 64,75 \mathrm{~b} \\ 13,50 \mathrm{~b} & 64,50 \mathrm{~b} \\ 29,00 & 52,75 \\ 42,50 \mathrm{~b} & 117,25 \mathrm{~b} \\ 21,09 & 35,44 \\ 57,43 & 44,89 \\ 66,41 & 64,42\end{array}$

$$
\begin{gathered}
14,10 \\
19,67 \\
5,62 \mathrm{~b} \\
-5,57 \\
14,05 \\
8,48 \mathrm{a} \\
-39,50 \\
71,43 \\
60,14 \mathrm{a}
\end{gathered}
$$

Flúor

Médias seguidas de letras diferentes na linha diferem $(\mathrm{P}<0,05)$ pelo teste Tukey.

EPM = Erro-padrão da média.

$\begin{array}{llr}228 \mathrm{~b} & 766 \mathrm{a} & 69,7 \\ 165,25 \mathrm{~b} & 459 \mathrm{a} & 43,2 \\ 94,75 \mathrm{~b} & 335,25 \mathrm{a} & 33,5 \\ 62,75 \mathrm{~b} & 307,00 \mathrm{a} & 33,5 \\ 70,50 & 123,75 & 13,8 \\ 133,25 \mathrm{~b} & 430,75 \mathrm{a} & 40,0 \\ 27,52 & 40,08 & 4,3 \\ 42,66 & 26,96 & 5,2 \\ 58,44 & 56,23 & 3,8\end{array}$

6,7 43,2 33,5 33,5 13,8 0,0

$\begin{array}{cr}14,11 & 0,2 \\ 20,88 & 1,6 \\ 6,92 \mathrm{a} & 0,2 \\ -6,77 & 1,6 \\ 13,96 & 1,6 \\ 7,19 \mathrm{~b} & 0,3 \\ -47,98 & 10,8 \\ 66,86 & 1,7 \\ 50,96 \mathrm{~b} & 1,4\end{array}$


taram os valores de 61,$70 ; 60,14$ e $58,89 \%$, respectivamente. Os animais que receberam suplementação com fosfato de rocha Araxá apresentaram menor $(\mathrm{P}<0,05)$ absorção aparente total $(50,96 \%)$ em relação ao fosfato bicálcico e fosfato monoamônio, mas foram semelhantes àqueles que receberam superfosfato triplo $(58,89 \%)$. Estes valores de absorção aparente são superiores aos encontrados por Silva Filho et al. (1992), de 32,22; 31,95 e 29,08\% para fosfato bicálcico, superfosfato triplo e fosfato monoamônio, respectivamente. Ekelund et al. (2003), trabalhando com vacas, encontraram absorção aparente de fósforo de 50\%, utilizando o fosfato monossódico e os farelos de canola, de girassol e de trigo como fontes de fósforo.

Reid (1980) menciona que o fósforo de fertilizantes fosfatados, como o supertriplo e fosfato monoamônio, são altamente disponíveis e que o uso dessas fontes na suplementação de animais domésticos é, na verdade, mais limitado pelo teor de flúor que pela absorção de fósforo. Convém salientar que os fertilizantes fosfatados estrangeiros de modo geral contêm altos níveis de flúor (NRC, 1974), enquanto os fertilizantes fosfatados nacionais normalmente possuem menores níveis desse elemento por serem produzidos a partir de rochas com baixo teor de flúor.

As exigências de fósforo sugeridas por comitês de diferentes países para animais semelhantes ao usados no experimento são de 11 (AFRC, 1991), 12 (NRC, 1996), 13 (Ternouth et al., 1996) até $14 \mathrm{~g} / \mathrm{dia}$ (NRC, 1984). Éinteressante notar que o valor estimado pelo AFRC (1991) foi calculado para dietas à base de concentrados e subiria para $17 \mathrm{~g} / \mathrm{dia}$ se corrigido para dietas contendo mais de $50 \%$ de forrageiras (Nicodemo et al., 2000).

A ingestão de flúor pelos animais que receberam fosfato de rocha Araxá foi maior $(\mathrm{P}<0,05)$, seguida pela daqueles que receberam fosfato monoamônio e superfosfato triplo. A menor foi para fosfato bicálcico, que foi semelhante $(\mathrm{P}>0,05)$ ao superfosfato triplo. A maior ingestão de flúor entre animais alimentados com fosfato de rocha Araxá está relacionada às altas concentrações do elemento nos fosfatos naturais e fertilizantes.

Os bovinos são mais sensíveis à intoxicação por flúor que outras espécies domésticas. O consumo contínuo de até $40 \mathrm{mg} \mathrm{F} / \mathrm{kg}$ MS pode ser tolerado por novilhas em crescimento, sem que o desempenho seja afetado, embora possa causar lesões patológicas, enquanto em bovinos adultos, esse valor é de $50 \mathrm{mg} \mathrm{F} / \mathrm{kg}$ MS (Nicodemo \& Moraes, 2000). Neste experimento, as ingestões diárias de flúor por $\mathrm{kg}$ de MS foram: 9,21;26,26;33,30 e 110,48 mg F/ $/ \mathrm{kg}$ MS para as fontes de fósforo fosfato bicálcico, superfosfato triplo, fosfato monoamônio e fosfato de rocha Araxá, respectivamente. O fosfato de rocha Araxá apresentou aproximadamente três vezes mais flúor que o limite recomendado por diferentes sistemas de nutrição. $\mathrm{O}$ fosfato bicálcico apresentou 12 vezes menos flúor que o fosfato de rocha Araxá e aproximadamente 25\% do limite de flúor que pode causar toxidez. O superfosfato triplo apresentou aproximadamente $50 \%$ do limite de flúor para bovinos adultos e o fosfato monoamônio valor um pouco menor que o limite para bovinos em crescimento.

O NRC (1974) afirma que a ingestão de flúor acima dos níveis considerados limites ( $100 \mu \mathrm{g} \mathrm{F} / \mathrm{kg}$ PV) induz a efeitos tóxicos na maioria dos animais. As fontes de fósforo utilizadas no experimento produziram ingestões diárias de 23,0; 65,$6 ; 81,5$ e $276,3 \mu \mathrm{g} \mathrm{F} / \mathrm{kg}$ PV, respectivamente para fosfato bicálcico, superfosfato triplo, fosfato monoamônio e fosfato de rocha Araxá. A ingestão de flúor quando se utilizou o fosfato bicálcico foi de aproximadamente $25 \%$ do limite recomendado, enquanto com o uso de fosfato de rocha Araxá foi aproximadamente três vezes acima do limite, o que com certeza prejudica os animais se utilizado por períodos prolongados (NRC, 1974), fato que não ocorreu no experimento, em razão do curto período de utilização (21 dias). As ingestões de flúor quando fornecidas as fontes superfosfato triplo e fosfato monoamônio mantiveram-se no limite máximo, assim, essas fontes podem ser boas opções em substituição ao fosfato bicálcico.

O consumo diário de flúor foi maior entre os animais que consumiram fosfato de rocha Araxá, os quais apresentaram também fluxo duodenal e fecal de flúor superiores $(\mathrm{P}<0,05)$ ao dos que consumiram as outras fontes, que não diferiram entre si $(\mathrm{P}>0,05)$. A maior ingestão de flúor refletiu-se também em maiores desaparecimentos ruminal e total de flúor $(\mathrm{P}<0,05)$ para os animais que receberam suplementação com fosfato de rocha Araxá, e foi semelhante para fosfato bicálcico, superfosfato triplo e fosfato monoamônio $(\mathrm{P}>0,05)$. $\mathrm{O}$ desaparecimento intestinal não diferiu entre as fontes de fósforo utilizadas $(\mathrm{P}>0,05)$. Os dados enfatizaram a absorção de flúor no rúmen.

Não houve diferença entre as fontes de fósforo quanto a absorção aparente ruminal, intestinal e total de flúor.

A digestibilidade aparente da matéria seca e da matéria orgânica não diferiu $(\mathrm{P}>0,05)$ entre as fontes de fósforo (Tabela 4). A digestibilidade aparente ruminal da MS variou de 47,14 a 55,59\% e a digestibilidade aparente total, de 63,56 a $64,75 \%$. Nicodemo et al. (2000), em pesquisa com novilhos e usando diferentes níveis de fósforo, inclusive um 50\% abaixo do recomendado pelo NRC (1984), não encontraram diferenças nas digestibilidades da matéria seca e da matéria orgânica da dieta. 
Não foi observada diferença $(\mathrm{P}>0,05)$ para ingestão, fluxo duodenal, fluxo fecal, coeficiente de digestibilidade aparente intestinal e coeficiente de digestibilidade total da fibra em detergente neutro nos animais que consumiram as diferentes fontes de fósforo (Tabela 4). Segundo Hungate (1966), baixas concentrações de fósforo no rúmen podem afetar a digestibilidade da fibra, pois limitam a atividade dos microrganismos, o que neste caso não ocorreu, uma vez que a digestibilidade ruminal de FDN foi superior a $52 \%$ e a digestibilidade total, acima de $61 \%$ para uma dieta contendo $77 \%$ de FDN.

As fontes de fósforo utilizadas no experimento promoveram resultados semelhantes $(\mathrm{P}>0,05)$ de ingestão, fluxo duodenal e fecal, e coeficientes de digestibilidade aparente ruminal, intestinal e total da proteína bruta e dos carboidratos não-fibrosos.

Os valores de nutrientes digestíveis totais, tanto observados quanto estimados por Weiss (1999), não apresentaram diferença significativa $(\mathrm{P}>0,05)$ entre as fontes de fósforo utilizadas, apesar de a estimativa dada pela equação de Weiss (1999) resultar em valores $12 \%$ superiores aos observados no experimento.

Ovinos e bovinos mantidos com dietas com teores deficientes a moderados de fósforo apresentaram boa correlação entre o consumo e a concentração plasmática de fósforo (Ternouth \& Sevilha, 1990; Silva Filho et al., 2000). A concentração plasmática de fósforo não foi influenciada (Tabela 5, P>0,05) pela fonte de fósforo

Tabela 4 - Ingestão, fluxo duodenal e fecal e digestibilidade aparente ruminal, intestinal e total dos nutrientes

\begin{tabular}{|c|c|c|c|c|c|}
\hline & \multicolumn{4}{|c|}{ Fonte de fósforo } & \multirow[t]{2}{*}{ EPM } \\
\hline Fos & sfato bicálcico & Superfosfato triplo & Fosfato monoamônio & Fosfato rocha Araxá & \\
\hline \multicolumn{6}{|c|}{ Matéria seca } \\
\hline Ingestão (g/dia) & $6.947,10$ & $6.931,18$ & $6.847,52$ & $6.933,49$ & 240,70 \\
\hline Fluxo duodenal (g/dia) & $3.404,80$ & $3.438,11$ & $3.040,87$ & $3.664,94$ & 150,10 \\
\hline Fluxo fecal (g/dia) & $2.528,50$ & $2.442,98$ & $2.495,44$ & $2.448,81$ & 69,40 \\
\hline Digestibilidade aparente ruminal $(\%)$ & 50,99 & 50,40 & 55,59 & 47,14 & 1,60 \\
\hline Digestibilidade aparente intestinal (\%) & 25,74 & 28,94 & 17,94 & 33,18 & 2,20 \\
\hline Digestibilidade aparente total $(\%)$ & 63,60 & 64,75 & 63,56 & 64,68 & 0,80 \\
\hline \multicolumn{6}{|c|}{ Matéria orgânica } \\
\hline Ingestão（g/dia） & $6.597,90$ & $6.583,66$ & $6.503,69$ & $6.583,12$ & 227,20 \\
\hline Fluxo duodenal (g/dia) & $3.156,10$ & $3.092,59$ & $2.768,43$ & $3.327,55$ & 139,30 \\
\hline Fluxo fecal (g/dia) & $2.277,60$ & $2.231,16$ & $2.217,80$ & $2.242,74$ & 114,30 \\
\hline Digestibilidade aparente ruminal $(\%)$ & 52,17 & 53,03 & 57,43 & 49,45 & 1,60 \\
\hline Digestibilidade aparente intestinal (\%) & 27,83 & 27,85 & 19,89 & 32,60 & 3,40 \\
\hline Digestibilidade aparente total $(\%)$ & 65,48 & 66,11 & 65,90 & 65,93 & 1,40 \\
\hline \multicolumn{6}{|c|}{ Fibra em detergente neutro } \\
\hline Ingestão (g/dia) & $5.387,70$ & $5.354,98$ & $5.283,20$ & $5.357,57$ & 195,60 \\
\hline Fluxo duodenal (g/dia) & $2.534,80$ & $2.300,83$ & $2.238,01$ & $2.445,37$ & 105,70 \\
\hline Fluxo fecal (g/dia) & $2.070,20$ & $1.968,60$ & $1.725,10$ & $1.985,26$ & 84,00 \\
\hline Digestibilidade aparente ruminal (\%) & 52,95 & 57,03 & 57,64 & 54,36 & 2,00 \\
\hline Digestibilidade aparente intestinal (\%) & 18,33 & 14,44 & 22,92 & 18,82 & 3,30 \\
\hline Digestibilidade aparente total $(\%)$ & 61,58 & 63,24 & 67,35 & 62,94 & 1,40 \\
\hline \multicolumn{6}{|c|}{ Proteína bruta } \\
\hline Ingestão (g/dia) & 850,07 & 849,88 & 837,59 & 850,15 & 30,60 \\
\hline Fluxo duodenal (g/dia) & 602,11 & 688,20 & 559,91 & 689,15 & 36,90 \\
\hline Fluxo fecal (g/dia) & 296,91 & 317,97 & 307,72 & 308,02 & 7,40 \\
\hline Digestibilidade aparente ruminal $(\%)$ & 29,17 & 19,02 & 33,15 & 18,94 & 3,40 \\
\hline Digestibilidade aparente intestinal (\%) & 50,69 & 53,80 & 45,04 & 55,30 & 2,80 \\
\hline Digestibilidade aparente total $(\%)$ & 65,07 & 62,59 & 63,26 & 63,77 & 1,00 \\
\hline \multicolumn{6}{|c|}{ Carboidratos não-fibrosos } \\
\hline Ingestão（g/dia） & 410,41 & 400,51 & 402,07 & 398,45 & 20,00 \\
\hline Fluxo duodenal (g/dia) & 332,44 & 337,44 & 326,32 & 252,58 & 69,40 \\
\hline Fluxo fecal (g/dia) & 156,92 & 103,85 & 135,89 & 118,53 & 150,10 \\
\hline Digestibilidade aparente ruminal (\%) & 19,00 & 15,75 & 18,84 & 36,61 & 28,80 \\
\hline Digestibilidade aparente intestinal (\%) & 52,80 & 69,22 & 58,36 & 53,07 & 8,80 \\
\hline Digestibilidade aparente total $(\%)$ & 61,77 & 74,07 & 66,20 & 70,25 & 4,70 \\
\hline
\end{tabular}

Médias seguidas de letras diferentes na linha diferem $(\mathrm{P}<0,05)$ pelo teste Tukey.

$\mathrm{EPM}=$ Erro-padrão da média. 
utilizada e todas as fontes foram eficientes em manter níveis adequados de fósforo no plasma, com média de $5,87 \mathrm{mg} / \mathrm{dL}$, ou seja, dentro dos limites considerados normais, que ficam entre 4 e $9 \mathrm{mg} / \mathrm{dL}$ (Thompson Jr., 1978).

Somente a concentração de fósforo no plasma não fornece uma indicação do status desse elemento no animal (Engles, 1981; Conrad et al., 1984), mas, junto com os demais dados levantados neste trabalho, dá suporte à tese de que, nas condições testadas, os fosfatos foram capazes de suplementar adequadamente o fósforo da dieta dos bovinos.

A ingestão de nitrogênio não foi afetada $(\mathrm{P}>0,05)$ pelas fontes de fósforo, uma vez que as dietas experimentais eram isonitrogenadas e o nível de ingestão foi pré-definido. $\mathrm{O}$ fluxo duodenal, a digestão ruminal e o coeficiente de digestibilidade ruminal de $\mathrm{N}$ não diferiram $(\mathrm{P}>0,05)$ entre as fontes de fósforo. $\mathrm{O}$ fluxo duodenal de nitrogênio bacteriano e o fluxo duodenal de nitrogênio não-bacteriano também não apresentaram diferença $(\mathrm{P}>0,05)$ entre as fontes de fósforo utilizadas.

As fontes de fósforo foram semelhantes ( $P>0,05)$ quanto à eficiência de síntese microbiana aparente e verdadeira. Segundo Komisarczuk et al. (1987), a síntese microbiana é afetada somente quando a suplementação de fósforo é insuficiente, o que não ocorreu neste experimento, mostrando que fosfato bicálcico, superfosfato triplo, fosfato monoamônio e fosfato de rocha Araxá podem suprir igualmente as exigências de fósforo dos microrganismos do rúmen se a concentração de fósforo da dieta estiver adequada à categoria animal e suas necessidades.

A eficiência de síntese microbiana aparente que variou de 31,20 a 34,36 gN bac/kg de MODR (gramas de nitrogênio bacteriano por quilograma de matéria orgânica degradada no rúmen), com valor médio foi de 33,05 $\mathrm{gN}$ bac $/ \mathrm{kg}$ de MODR. Esse valor se encontra na faixa de valores revisados por Valadares Filho (1995) a partir de trabalhos nacionais, nos quais a variação da eficiência de síntese microbiana aparente foi de 25,65 a 38,50 $\mathrm{gN}$ bac/kg de MODR e o valor médio, de 33,40 gN bac/kg de MODR.

A eficiência de síntese microbiana verdadeira variou de 20,5 a 22,1 $\mathrm{gN} \mathrm{bac} / \mathrm{kg}$ de MODR, com média de 21,5 gN bac/kg de MODR, e também não foi influenciado $(\mathrm{P}>0,05)$ pela fonte de fósforo. Os resultados de eficiência de síntese microbiana confirmam os resultados obtidos para digestibilidade ruminal aparente da matéria seca, matéria orgânica, proteína bruta, fibra em detergente neutro e carboidratos não-fibrosos (Tabela 6).

A determinação da composição microbiana é importante (Tabela 7), pois as dietas são formuladas para que os

Tabela 5 - Nutrientes digestíveis totais observados e estimados e fósforo plasmático

\begin{tabular}{lrrrr}
\hline Nutrientes digestíveis totais ${ }^{2}$ & \multicolumn{2}{c}{ Fonte de fósforo } \\
\cline { 2 - 3 } & Fosfato bicálcico & Superfosfato triplo & Fosfato monoamônio & Fosfato rocha Araxá \\
\hline Observados (\%) & 59,22 & 62,17 & 61,40 \\
Estimados (\%) & 68,22 & 68,22 & 5,89 \\
P plasma (mg/dL) & 5,97 & 5,86 & 68,22 & 5,22 \\
\hline
\end{tabular}

Médias seguidas de letras diferentes na linha diferem $(\mathrm{P}<0,05)$ pelo teste Tukey.

${ }^{1}$ Calculados segundo Weiss (1999).

$\mathrm{EPM}=$ Erro-padrão da média.

Tabela 6 - Eficiência de síntese microbiana

\begin{tabular}{|c|c|c|c|c|c|}
\hline & \multicolumn{4}{|c|}{ Fonte de fósforo } & \multirow[t]{2}{*}{ EPM } \\
\hline & Fosfato bicálcico & Superfosfato triplo & Fosfato monoamônio & Fosfato rocha Araxá & \\
\hline Ingestão média diária (g/dia) & 136,01 & 135,98 & 134,01 & 136,02 & 4,89 \\
\hline Fluxo duodenal (g/dia) & 116,34 & 114,60 & 89,59 & 94,26 & 8,34 \\
\hline Digestão ruminal (g/dia) & 39,67 & 25,86 & 44,43 & 25,76 & 5,17 \\
\hline $\begin{array}{l}\text { Digestibilidade ruminal do } \\
\text { nitrogênio }(\%)\end{array}$ & 29,17 & 19,02 & 33,15 & 18,94 & 3,43 \\
\hline $\begin{array}{l}\text { Fluxo duodenal de nitrogênio } \\
\text { bacteriano ( } \mathrm{g} / \mathrm{dia})\end{array}$ & 72,18 & 80,52 & 74,04 & 70,16 & 3,83 \\
\hline $\begin{array}{l}\text { Fluxo duodenal de nitrogênio } \\
\text { não-bacteriano ( } \mathrm{g} / \mathrm{dia})\end{array}$ & 44,16 & 34,08 & 15,54 & 24,10 & 8,77 \\
\hline $\begin{array}{l}\text { Síntese microbiana aparente } \\
\text { (g N/kg MODR) }\end{array}$ & 34,36 & 34,14 & 32,49 & 31,20 & 4,07 \\
\hline $\begin{array}{l}\text { Síntese microbiana verdadeira } \\
\text { (g N/kg MODR) }\end{array}$ & 22,14 & 21,89 & 21,48 & 20,53 & 1,74 \\
\hline
\end{tabular}

Médias seguidas de letras diferentes na linha diferem $(\mathrm{P}<0,05)$ pelo teste Tukey.

$\mathrm{EPM}=$ Erro-padrão da média 
Tabela 7 - Matéria seca, matéria orgânica e nitrogênio das bactérias ruminais, pH e nitrogênio amoniacal do líquido ruminal

\begin{tabular}{|c|c|c|c|c|c|}
\hline & \multicolumn{4}{|c|}{ Fonte de fósforo } & \multirow[t]{2}{*}{ EPM } \\
\hline & Fosfato bicálcico & Superfosfato triplo & Fosfato monoamônio & Fosfato rocha Araxá & \\
\hline Matéria seca $(\%)$ & 90,24 & 93,03 & 90,96 & 92,19 & 0,80 \\
\hline Matéria orgânica (\%) & 78,43 & 87,70 & 89,42 & 87,04 & 2,00 \\
\hline Nitrogênio (\%) & 6,07 & 5,83 & 6,26 & 5,61 & 0,20 \\
\hline $\mathrm{pH}$ & 6,59 & 6,58 & 6,52 & 6,54 & 0,06 \\
\hline $\mathrm{N}-\mathrm{NH}_{3}(\mathrm{mg} / 100 \mathrm{~mL})$ & 15,75 & 16,24 & 18,07 & 17,79 & 1,09 \\
\hline
\end{tabular}

Médias seguidas de letras diferentes na linha diferem $(\mathrm{P}<0,05)$ pelo teste Tukey.

$\mathrm{N}-\mathrm{NH}_{3}=$ nitrogênio amoniacal.

$\mathrm{EPM}=$ Erro-padrão da média.

aminoácidos que escapam da degradação ruminal completem os aminoácidos bacterianos, pois os trabalhos de pesquisa indicam que a proteína microbiana corresponde, na maioria das dietas para ruminantes, a mais de $50 \%$ da proteína que chega ao intestino delgado (Clark et al., 1992).

As fontes de fósforo não afetaram $(\mathrm{P}>0,05)$ os teores de matéria seca, matéria orgânica e nitrogênio bacteriano. Os valores de matéria seca encontrados variaram de 90,2 a 93,0\% e estão na faixa de variação dos valores citados por Valadares Filho (1995), de 81,1 a 95,7\%.

O valor médio de matéria orgânica encontrado $(85,7 \%)$ foi próximo ao obtido por Valadares Filho (1995), média de dez experimentos (84,6\%), e pouco acima do encontrado por Clark et al. (1992), de 77,5\%. A matéria orgânica microbiana que sai do rúmen está relacionada à matéria orgânica que é degradada no rúmen e a eficiência com que os microrganismos utilizam a energia disponível para seu crescimento (Owens \& Goetsch, 1993).

A concentração de $\mathrm{N}$ nas bactérias ruminais $(5,9 \%)$ está abaixo das encontradas Clark et al. (1992), de 7,7\%, porém está próxima das encontradas por Guimarães et al. (2001), de 5,8 a 6,2\% e dentro da variação encontrada por Valadares Filho (1995), de 5,2 a 8,7\%. O nitrogênio microbiano é uma importante informação, pois as exigências protéicas dos ruminantes são atendidas através da proteína microbiana e da proteína não-degradada no rúmen (Valadares Filho, 1995).

As fontes de fósforo não apresentaram diferenças ( $\mathrm{P}>0,05)$ quanto aos valores de $\mathrm{pH}$ ruminal (Tabela 7), que variaram de 6,12 a 6,86 (Figura 1). O fosfato bicálcico e o superfosfato triplo apresentaram o menor pH 6 horas após a alimentação, enquanto para fosfato monoamônio e fosfato de rocha Araxá isto ocorreu após 4 horas. Os valores mínimos para fosfato bicálcico, superfosfato triplo, fosfato monoamônio e fosfato de rocha Araxá foram 6,43; 6,52; 6,12 e 6,24, respectivamente. Este decréscimo no pH é resultante do intenso processo de fermentação e do conseqüente aumento dos ácidos graxos voláteis (Ørskov, 1988) após o fornecimento do alimento. Com exceção do fosfato monoamônio, todos os valores mínimos de $\mathrm{pH}$ mantiveram-se acima de 6,2, considerado por Ørskov (1988) e Hoover (1986) limite mínimo de $\mathrm{pH}$ para adequada fermentação da fibra por não prejudicar os microrganismos celulolíticos, porem esse menor $\mathrm{pH}$ encontrado no fosfato monoamônio não afetou a digestibilidade da fibra (Tabela 4) e a eficiência de síntese microbiana (Tabela 6).

Não houve diferenças $(\mathrm{P}>0,05)$ nos valores de nitrogênio amoniacal entre as fontes de fósforo (Tabela 7). As concentrações de nitrogênio amoniacal no líquido ruminal se mantiveram entre 5,44 e 47,91 mg/100 mL (Figura 2), com

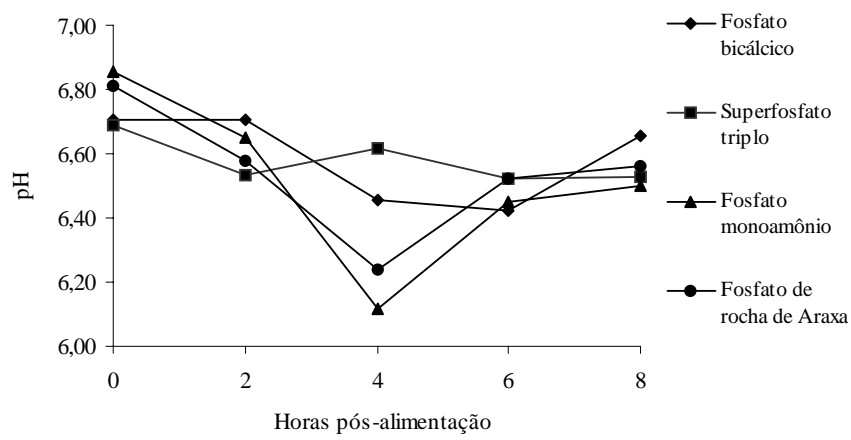

Figura 1 - pH ruminal durante o período de 8 horas após a alimentação.

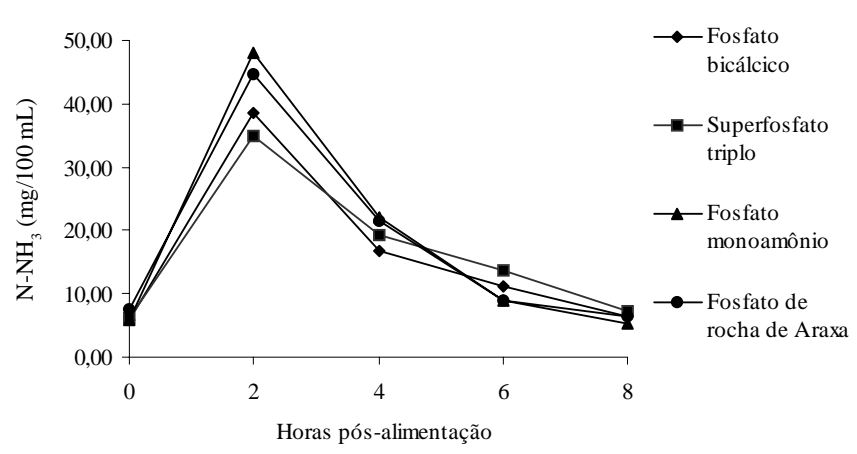

Figura 2 - Concentração de $\mathrm{N}-\mathrm{NH}_{3}$ ruminal durante o período de 8 horas após a alimentação. 
os maiores valores ocorrendo 2 horas após a alimentação e os menores valores imediatamente antes das alimentações.

Para todas as fontes de fósforo, os valores médios de concentração de amônia ruminal mantiveram-se em níveis superiores a $5 \mathrm{mg} / \mathrm{dL}$ (Sater \& Slyter, 1974), considerado mínimo para adequada fermentação ruminal da parede celular. Entretanto, quando considerados os valores de concentração de amônia ruminal preconizados por Leng (1990), ou seja, $20 \mathrm{mg} / \mathrm{dL}$ de líquido ruminal, como ideais para aumento do consumo voluntário em condições tropicais, verificou-se que, em todos os tratamentos, em alguns horários, as concentrações foram inferiores aos valores sugeridos.

\section{Conclusões}

O fosfato de rocha de Araxá apresenta menor absorção aparente total do fósforo, em comparação aos fosfatos bicálcico e monoamônio, e retenção de quantidades elevadas de flúor que podem produzir intoxicação nos animais alimentados por longos períodos. O superfosfato triplo e o fosfato monoamônio podem substituir o fosfato bicálcico por apresentarem semelhança na absorção aparente total do fósforo, não produzirem ingestão de flúor superior aos limites sugeridos como seguros e apresentarem digestibilidade semelhante dos nutrientes da dieta.

\section{Literatura Citada}

AGRICULTURAL AND FOOD RESEARCH COUNCIL - AFRC. Technical Committee on Responses to Nutrients. A reappraisal of the calcium and phosphorus requirements of sheep and cattle. Nutrition Abstracts and Reviews: Series B Livestock Feeds and Feeding, Wallingford, v.61, n.9, p.573-612, 1991.

ASSOCIATION OF OFFICIAL ANALITICAL CHEMISTS AOAC. Official methods of analysis. 15.ed. Arlington: 1990. $1117 \mathrm{p}$

BARCELLOS, J.O.J. O papel de fósforo na nutrição de bovinos de corte. In: DIAZ GONZALEZ, F.H.; OSPINA, H.; BARCELLOS, J.O.J. (Eds.) Nutrição mineral em ruminantes. 2.ed. Porto Alegre: Editora da UFRGS, 1998. p.23-72.

BEN-GHEDALIA, D.; ZAQARI, H.; ZOMWELL S. et al. Solubility and net exchange of calcium, magnesium and phosphorus in digesta flowing along the gut of the sheep. British Journal of Nutrition, v.33, p.87, 1975.

BOHNERT, D.W.; LARSON, B.I.; BAUER, M.L. et al. Nutritional evaluation of poultry by-product meal as a protein source for ruminants: effects on performance and nutrient flow and disappearance in steers. Journal of Animal Science, v.76, p.2474-2484, 1998.

CECAVA, M.J.; MERCHEN, N.R.; GAY, L.C. et al. Composition of ruminal bacteria harvested from steers as influenced by dietary energy level, feeding frequency and isolation techniques. Journal of Dairy Science, v.73, n.9, p.2480-2488, 1990.

CHICCO, C.F.; AMMERMAN, C.B.; MOORE, J.E. et al. Utilization of inorganic ortho-, meta-, and pyrophosphates by lambs and by cellulolytic rumen micro-organisms in vitro. Journal Animal Science, v.24, p.355-363, 1965
CLARK, J.H.; KLUSMEYER, T.H.; CAMERON, M.R. Microbial protein synthesis and flows of nitrogen fractions to the duodenum of dairy cows. Journal of Dairy Science, v.75, n. 8, p.2304-2323, 1992 .

CONRAD, J.H.; McDOWELL, L.R.; ELLIS, G.L. et al. Resultado de 10 anos de pesquisa em nutrição mineral com animais em pastejo nos trópicos. In: REUNIÃO ANUAL DA SOCIEDADE BRASILEIRA DE ZOOTECNIA, 21., 1984, Belo Horizonte. Anais... Belo Horizonte: Sociedade Brasileira de Zootecnia, 1984. p. 352 .

EKELUND, A.; SPÖRNDLY, R.; VALK, H. et al. Influence of feeding various phosphorus source on apparent digestibility of phosphorus in dairy cows. Animal Feed Science and Technology, v.109, n.1, p.95-104, 2003.

ENGLES, E.A.N. Mineral grazing status and profiles (blood, bone and milk) of the grazing ruminant with special reference to calcium, phosphorus and magnesium. South African Journal of Animal Science, v.11, n.2, p.171-182, 1981.

FENNER, H. Method for determining total volatile bases in rumen fluid by steam distillation. Journal of Dairy Science, v.48, n.2, p.249-251, 1965.

FISKE, C.H.; SUBBAROW, Y. The colorimetric determination of phosphorus. Journal of Biological Chemistry, v.66, p.375, 1925.

FORBES, J.M.; FRANCE, J. Quantitative aspects of ruminant digestion and metabolism. Wallingford: $C A B$ International, 1993. $515 \mathrm{p}$.

GEORGIEVSKII, V.I. The physiological role of macro-elements. In: GEORGIEVSKII, V.I.; ANNENKOV, B.N.; SAMOKHIN, V.I. (Eds.) Mineral nutrition of animals. London: Butterworths, 1982. p. $91-170$.

GUIMARÃES, K.C.; BRANCO, A.F.; ZEOULA, L.M. et al. Efeito do período experimental sobre a fermentação ruminal e eficiência de síntese microbiana em bovinos alimentados com dois níveis de volumosos. Revista Brasileira de Zootecnia, v.30, n.3, p.880-887, 2001.

HOOVER, W.H. Chemical factors involved en ruminal fiber digestion. Journal of Dairy Science, v.69, n.10, p.2755-2766, 1986.

HUNGATE, R.E. The rumen and its microbes. New York: Academic Press, 1966. p.346-347.

KARN, J.F. Phosphorus nutrition of grazing cattle: a review. Animal Feed Science and Technology, v.89, n.3, p.133-153, 2001.

KOMISARCZUK, S.; MERRY, R.J.; McALLAN, A.B. Effect of different levels of phosphorus on rumen microbial fermentation and synthesis determined using a continuous culture technique. British Journal of Nutrition, v.57, p.279-290, 1987.

LENG R.A Factors affecting the utilization of poor quality forages by ruminants particularly under tropical conditions. Nutrition Research Revision, v.3, p.277-303, 1990.

LITTLE, D.A.; ROBINSON, P.J. ; PLAYNE, M.J. et al. Factors affecting blood inorganic phosphorus in cattle. Australian Veterinary Journal, v.47, p.53, 1971.

NATIONAL RESEARCH COUNCIL - NRC. Feed phosphorus shortage: level and sources of phosphorus recommended for livestock and poultry. Washington, D.C.: National Academy of Science, 1974. 38p.

NATIONAL RESEARCH COUNCIL - NRC. Nutrient requirements of beef cattle. 7.ed. Washington, D.C.: National Academy Press, 1996. 242p.

NATIONAL RESEARCH COUNCIL - NRC. Nutrient requirements of beef cattle. 6.ed. Washington, D.C.: National Academy of Science, 1984. 90p.

NICODEMO, M.L.F.; MORAES, S.S. Esclarecimentos sobre o uso de fontes alternativas de fósforo para bovinos. Campo Grande: Embrapa Gado de Corte, 2000. (Divulgação).

NICODEMO, M.L.F.; MORAES, S.S.; ROSA, I.V. et al. Avaliação de níveis de fósforo na dieta de novilhos Nelore em crescimento: efeito no desempenho. Revista Brasileira de Zootecnia, v.29, n.4, p.1191-1195, 2000. 
ØRSKOV, E.R. Nutricion proteica de los ruminantes. Zaragoza: Acribia, 1988. 178p.

OWENS, F.N.; GOETSCH, A.L. Fermentación ruminal. In: CHURCH, D.C. (Ed.) El ruminante, fisiologia digestiva y nutrición: Zaragoza: Acríbia, 1993. p.159-190.

REID, R.L. Relationship between phosphorus nutrition of plants and phosphorus nutrition of animals and man. In: KHAWNEH, F.E.; SAMPLE, E.C.; KAMPRATH, E.J. The role of phosphorus in agriculture. [S.1.]: American Society of Agronomy, 1980. p.847-886.

ROSOL, C.; CAPEN, C. Calcium-regulating hormones and diseases of abnormal mineral (calcium, phosphorus, magnesium) metabolism. In: KANEKO, J.J (Ed.) Clinical biochemistry of domestic animals. 5.ed. New York: Academic Press, 1997. p.619-702.

SATTER, L.D.; SLYTER, L.L. Effect of ammonia concentration on rumen microbial production in vitro. British Journal Nutrition, v.32, n.2, p199-208, 1974.

SILVA FILHO, J.C.; LOPES, H.O.S.; PEREIRA, E.A. et al. Absorção real do fósforo do fosfato bicálcico, fosfato de monoamônio; superfosfato triplo e o fosfato de uréia em bovinos. Pesquisa Agropecuária Brasileira, v.27, n.1, p.1-6, 1992.

SILVA FILHO, J.C.; VITTI, D.M.S.S.; CAMPOS NETO, O. et al. Exigência mínina de fósforo em novilhos da raça nelore. Pesquisa Agropecuária Brasileira, v.35, n.9, p.1861-1865, 2000.

SINGER, L.; ARMSTRONG, W.D. Determination of fluoride in bone with the fluoride eletrode. Analytical Chemistry, v.40, p.613-614, 1968.

SNIFFEN, C.J.; O'CONNOR, J.D.; Van SOEST, P.J. et al. A net carbohydrate and protein system for evaluation cattle diets: II. Carbohydrates and protein availability. Journal of Animal Science, v.70, n.11, p.3562-3577, 1992.

TERNOUTH, J.H.; SEVILLA, C.L. Dietary calcium and phosphorus repletion in lambs. Australian Journal of Agricultural Research, v.41, p.413-420, 1990.

TERNOUTH, J.H; BORTOLUSSI, G.; COATES, D.B. et al. The phosphorus requirements of growing cattle consuming forage diets. Journal of Agricultural Science, v.126, p.503, 1996.

THOMPSON JR., W.R. Phosphorus in animal nutrition. In: POTASH AND PHOSPHATE INSTITUTE. Phosphorus for agriculture a situation analysis. Atlanta: 1978. p.126-158.
UNDERWOOD E.J.; SUTTLE N.F. The mineral nutrition of livestock. 3.ed. Wallingford: CABI Publication, 1999. 614p.

UNIVERSIDADE FEDERAL DE VIÇOSA - UFV. SAEG - Sistema de análises estatísticas e genéticas. Versão7.1 Viçosa, MG: 1997. 150p. (Manual do usuário).

USHIDA, K.; LASSALAS, B.; JOUANK, J.P. Determination of assay parameters for RNA analysis in bacterial and duodenal samples by spectrophotometry. Influence of sample treatment and preservation. Reproduction, Nutrition, Development, v.25, p.1037-1044. 1985.

VALADARES FILHO, S.C. Eficiência de síntese de proteína microbiana, degradação ruminal e digestibilidade intestinal da proteína bruta, em bovinos. In: SIMPÓSIO INTERNACIONAL SOBRE EXIGÊNCIAS NUTRICIONAIS DE RUMINANTES, 1995, Viçosa, MG. Anais... Viçosa, MG: Universidade Federal de Viçosa, 1995. p.355-388.

Van SOEST, P.J.; ROBERTSON, J.B.; LEWIS, B.A. Symposium: methods for dietary fiber, neutral detergent fiber, and nonstarch polysaccharides in relation to animal nutrition. Journal of Dairy Science, v.74, n.10, p.3583-3597, 1991.

VIEIRA, P.F. Efeito do formaldeído na proteção de proteínas e lipídios em rações para ruminantes. 1980. 98f. Tese (Doutorado em Zootecnia) - Universidade Federal de Viçosa, Viçosa, MG, 1980.

VITTI, D.M.S.S.; LOPES, J.B.; SILVA FILHO, J.C. et al. Phosphorus flow from different phosphate sources in cattle. Arquivo Brasileiro de Medicina Veterinária e Zootecnia, v.53, n.2, p.1-7, 2001.

WEISS, W.P. Energy prediction equations for ruminant feeds. In: CORNELL NUTRITION CONFERENCE FOR FEED MANUFACTURERS, 1999, Rochester. Proceedings... Rochester: New York State College of Agriculture \& Life Sciences, Cornell University, 1999. p.176-185.

WILLIAMS, C.H.; DAVID, D.J.; IISMAA, O. The determination of chromic oxide in feces samples by atomic spectrophotometry. Journal of Agricultural Science, v.59, p.381-385, 1962.

WITT, K.E.; OWES, F.M. Phosphorus ruminal availability and effects on digestion. Journal of Animal Science, v.56, n.4, p.930-937, 1983 . 